\title{
A Modified Strain Gradient Beam Constraint Model
}

\author{
Mohammad Arhami ${ }^{1}$ and Hamid Moeenfard ${ }^{1}$ \\ ${ }^{1}$ Ferdowsi University of Mashhad Faculty of Engineering
}

November 4, 2021

\begin{abstract}
The objective of this paper is to develop a modified strain gradient beam constraint model (MSGBCM) to improve modeling accuracy of small-scale compliant mechanisms. First, a simple nano/micro flexure beam under the effect of end loads is considered. The virtual work principle is employed to formulate the load-displacement behavior of the system based on the modified strain gradient theory. It is observed that as the size of the structure becomes smaller, the elements of the elastic stiffness and load stiffening matrices severely deviate from their corresponded values in the beam constraint model (BCM). Then, a closed-form expression is proposed for the nonlinear strain energy of the nano/micro flexure beams in terms of their tip displacements. This energy expression is then utilized to model load-displacement relationship of micron/submicron size parallelogram (P) flexures. Moreover, analytical formulas are derived for the axial, transverse and rotational stiffnesses of P-flexures. The most important observation is that the axial stiffness loss of small-scale P-flexures resulted from the movement of the stage in the transverse direction, may be seriously overestimated by the BCM. The MSGBCM developed in this paper can be easily extended for investigating static and dynamic behavior of more complex micron and submicron size flexure units.
\end{abstract}

\section{Hosted file}

MSGBCM.docx available at https://authorea.com/users/444562/articles/544263-a-modifiedstrain-gradient-beam-constraint-model

\section{Hosted file}

MSGBCM.pdf available at https://authorea.com/users/444562/articles/544263-a-modified-straingradient-beam-constraint-model 